\title{
The United States Particle Accelerator School: Educating the next generation of accelerator scientists and engineers
}

\author{
William A. Barletta ${ }^{1}$ \\ USPAS and Department of Physics, Massachusetts Institute of Technology, Cambridge, MA
}

ABSTRACT

Only a handful of universities in the US offer any formal training in accelerator science. The United States Particle Accelerator School (USPAS) is National Graduate Educational Program that has developed a highly successful educational paradigm that, over the past twenty-years, has granted more university credit in accelerator / beam science and technology than any university in the world. Sessions are held twice annually, hosted by major US research universities that approve course credit, certify the USPAS faculty, and grant course credit. The USPAS paradigm is readily extensible to other rapidly developing, crossdisciplinary research areas such as high energy density physics.

PACS: 01.40.Di, 01.40.Fk

Keywords: Education, Accelerator science and technology, Student training

\section{Introduction:}

Accelerators are essential engines of discovery in fundamental physics, biology, and chemistry. Particle beam-based instruments in medicine, industry and national security constitute a multi-billion dollar per year industry. More than 55,000 peer-reviewed papers having accelerator as a keyword are available on the Web. Yet only a handful of US universities offer any formal graduate program in accelerator science and its core technologies. Several reasons can be cited: 1) The science and technology of particle beams and other non-neutral plasmas cuts across traditional academic disciplines. 2) Electrical engineering departments have evolved toward micro- and nano-technology and computing science. 3) Nuclear engineering departments have atrophied at many major universities. 4) With few exceptions, student interest at individual universities is not extensive enough to support a strong faculty line. 5) Funding agency support of university-based accelerator research is generally insufficient to support a faculty line.

Education in accelerator physics and technology is vital to the national interest. In May 2008, the P5 Sub-

\footnotetext{
${ }^{1}$ Director, US Particle Accelerator School. Email address: barletta@mit.edu This work was supported by Fermi Research Alliance, LLC under Contract No. DE-AC02-07CH11359 with the U.S. Department of Energy.
} 


\section{Manuscript No. 441}

panel of HEPAP reaffirmed [P5_2008] the crucial role of particle accelerators in meeting the mission of the DOE Office of Science and the National Science Foundation. "Innovations in accelerator science and technology have made possible remarkable discoveries in particle physics over the past 60 years. Today, accelerators are critical not only to particle physics but to other programs in the Office of Science and to the national scientific enterprise. Beyond their purely scientific applications, they offer significant benefits for the nation's health, economy and security.” Indeed of the more than 15,000 accelerators operating worldwide, less than $0.2 \%$ (albeit the largest and most expensive machines) are used for scientific research, the remainder are operated for reasons of their benefit to "health, economy and security."

The judgment of P5_2008 echoed an earlier opinion of the National Research Council in its EPP2010 report that highlighted the importance of accelerators and accelerator R\&D as a critical element of a worldcompetitive US particle physics program. Moreover, in 2006 the HEPAP Sub-panel on the Assessment of Advanced Accelerator Research and Development (Marx Sub-panel) has noted [AARD_2006] that, “The future of accelerator-based science and applications will be limited unless new ideas and new accelerator directions are developed. Likewise, the demands for trained accelerator professionals far exceed what can be provided by today's limited educational opportunities... The sub-panel finds that there is an urgent need to strengthen accelerator science, technology and education in the US in order to address long-term needs of particle physics, other sciences and the nation.” The panel continues continue that, "The education and the training of the next generation of accelerator scientists and engineers is a serious concern. The limited number of educational opportunities at universities is insufficient to meet anticipated future needs.”2 The USPAS is dedicated to responding to this challenge.

Since its founding in 1982 by Dr. Melvin Month, the leadership of the US Particle Accelerator School has recognized and has continually acted to remediate this limitation. The guiding vision of the USPAS is to be an essential partner of U.S. universities and the national laboratories in training the next generation of accelerator scientists and technologists for the challenging accelerators of the future. The USPAS mission follows directly: provide a rigorous educational program in the science of particle beams and their associated accelerator technologies.

2 Report of the HEPAP Sub-panel on the Assessment of Advanced Accelerator Research and Development, July 11, 2006 


\section{Manuscript No. 441}

To meet that challenging mission the United States Particle Accelerator School (USPAS) has been established as National Graduate Educational Program that has developed a highly successful educational paradigm. Since its first program of rigorous academic courses began in 1987, USPAS has conducted more courses and issued more academic credit in the areas of accelerator science and its supporting technology than any university in the world. Because its rigorous program of academic courses is unmatched by programs in other parts of the world, the USPAS has become a growing force in the education of accelerator scientists and engineers internationally. The USPAS also promotes the writing and publication of textbooks devoted to accelerator science and technology. The USPAS paradigm is readily extensible to other rapidly developing, cross-disciplinary research areas such as high energy density physics.

\section{Governance}

USPAS is governed and funded by a 12-member consortium of seven national laboratories of the Office of Science of the Department of Energy (DOE), two national laboratories of the National Nuclear Security Agency of DOE, and two NSF university laboratories. This year the Transformational and Applied Research Directorate of the Domestic Nuclear Detection Office of the Department of Homeland Security joined the consortium. Each consortium member is entitled to one representative on the USPAS Board of Governors, which elects a Chair and appoints the USPAS Director, the chief executive of the School. The USPAS Director is responsible for developing the course offerings for the USPAS sessions with the advice of a Curriculum Advisory Committee composed of representatives from each consortium member plus representatives from universities with accelerator science programs.

The administrative office of USPAS, which performs and coordinates all functions and activities of the School, is funded by the Office of High Energy Physics and is located at Fermilab, which provides fiduciary oversight of the School activities. The USPAS Office has a full-time staff that provides all planning, organization, and on-site management for the School. The office handles advertising, collection of student applications and acceptance notification, faculty arrangements, distribution of course materials, and all other local arrangements.

\section{The USPAS Program and Curriculum}

Sessions are held twice annually, in January and in June, and are hosted by major US research universities 
that approve course content, certify the USPAS faculty, and grant course credit. The sessions run 10 days in duration. Students may register for one full course ( $>45$ contact hours) or they may choose two halfcourses (>22.5 contact hours each) where each half-course is one-week in duration. By successfully completing the course requirements that include lectures, graded daily problem sets, and examinations, students can earn university credit. A full-course earns the equivalent ${ }^{3}$ of 3 semester hours of host university credit; each half-course earns the equivalent of 1.5 semester hours of credit. As all courses run in parallel, students can take one full course, or two half-courses, or they may opt for only one half-course during either week of the program. The course prerequisites are minimally classical mechanics and electromagnetism at the senior undergraduate level. Specific prerequisites are listed in each course description. Exception to the prerequisites is at the discretion of the course instructor.

Typically the session is held at a hotel in the general vicinity of the host university. Both breakfast and dinner are provided to students. This arrangement maximizes the time available for formal instruction, study and informal discussions between students and USPAS faculty. Graduate students and post-docs may request scholarship support that includes the session fee and lodging; supported students share a room. USPAS also provides textbooks as requested by instructors at no additional cost to the students. Grades are reported to the host university, which will provide the students a transcript on request.

USPAS offers a highly varied, responsive, and balanced curriculum of science, engineering, computational and hands-on courses. These offerings, distributed as shown in Figure 1 include :

- General principles of accelerator physics, design of storage rings and synchrotrons, linacs, intense beam accelerators, beam optics, spin dynamics

- Experimental techniques, microwave measurement and beam instrumentation labs, accelerator vacuum labs, beam manipulation techniques

- Synchrotron radiation sources, free electron lasers, strong field radiation,

- Beam theory, non-linear dynamics, collective effects, beam instabilities,

- $\quad$ RF systems, magnetic systems, superconducting magnets, superconducting RF, superconducting materials, beam sources

- Computational methods in beam dynamics, beam optics and electromagnetism,

- Radiation physics and accelerator safety, radiation effects,

- Accelerator applications in medicine, research, and industry.

\footnotetext{
${ }^{3}$ Some of our hosts are on the quarter system; in that case an equivalent quarter credit is awarded.
} 
Each year we offer one or more hands-on laboratory courses in which students learn to use sophisticated instrumentation such as network analyzers, fiber lasers, etc. Agilent Technologies, Inc generously loans complex and expensive equipment for our Microwave Measurements course at no cost to USPAS. For the Winter 2008 Session USPAS faculty developed two new hands-on laboratory courses "Synchrotron LightBased Beam Diagnostics” and “Timing, Synchronization and Phase Control,” a critical topic for future light sources and free electron lasers.

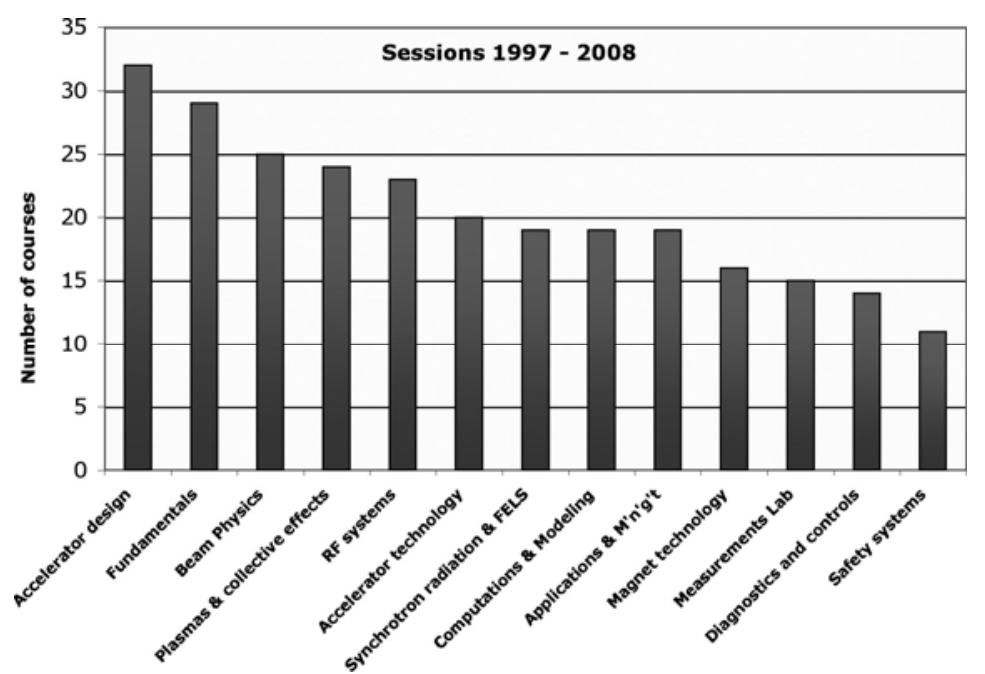

Figure 1. The distribution of courses covers the broad range of interest to the USPAS constituency

As universities generally require that course descriptions and instructor CVs be submitted roughly one year in advance of the session, the USPAS Director fixes the curricula and confirms the instructors eighteen months in advance of the sessions. The sessions also include a guest lecture concerning a prominent theme in accelerator-based science to enhance student awareness of opportunities in the accelerator field and to increase the utility of the USPAS programs for its laboratory and government sponsors. Special lectures on “Preparing Scientific Journal Articles” and “Interviewing Skills” have also been offered.

As is common at most US universities, at the completion of each course students provide an evaluation of the course content selected by our faculty and of the quality of the instruction. These data provide feedback to the Director and Curriculum Advisory Committee as well as to the individual instructors. The results from the 2008 sessions are representative of past results: more than $80 \%$ give the course and overall rating of "excellent” or "very good" and 80\% rate the instructors as "excellent” or "very good.” Only a few percent rate the courses or instructors as less than "good." 


\section{Student participation}

Interest in the USPAS and its academic program remains strong. The USPAS has attracted more than 4,200 attendees ( 3,000 individuals) in its 38 academic sessions since the first such program at the University of Chicago in 1987. Originally serving as a continuing education program for employees of and students at our sponsoring institutions, the USPAS now boasts a student population consisting of approximately $60 \%$ graduate and post-graduate students from universities and research institutions around the world. Of the 130 students who attend each session, roughly two-thirds enroll for university credit ${ }^{4}$; at the Summer 2008 Session more than $80 \%$ took the courses for credit. One-third of our students attend two or more sessions. Attendance has remained roughly constant over the past few years, indicating a continuing strong interest by our constituents. In fact, the attendance of 294 students in the Winter 2008 Session in Santa Rosa and our Summer Session at Annapolis is a very close second to the highest attendance ever (298 students in 1997) and much more than the annual average.

The USPAS remains an unparalleled source of continuing education for accelerator scientists and technologists for our national laboratories that account for half of the student enrollment. Not surprisingly the institutions that historically have had largest accelerator operations (and largest operating budgets) send the largest numbers of participants. For the future, USPAS aims to increase participation from the multiprogram laboratories with a goal of increasing average session attendance to $\sim 145$. The approach will be both through curriculum modification (for example, specialized engineering and forefront technology courses) and by greater advertising within the laboratories.

The USPAS reaches a broad international audience of students reflecting both the relative increase in accelerator projects in Europe and Asia as compared with the US and the student preferences for rigorous, intense academic courses that are the distinguishing hallmark of the USPAS curriculum as compared with the seminar-style courses given elsewhere in the world. Approximately 25\% of USPAS students travel from outside the United States to attend USPAS/university-sponsored programs. The Summer 2008 Session had participants from more than twenty countries. Based on legal consultation with immigration attorneys,

\footnotetext{
${ }^{4}$ Students from abroad without a student visa may not receive credit. If they request financial aid they agree to complete all the graded homework and exams. However, such students are included in this percentage.
} 
the USPAS policy concerning international participants has been carefully structured to be consistent with present US visa policies and procedures.

\section{USPAS faculty}

The heart of the USPAS instructional program is the USPAS faculty. With the advice of the Curriculum Advisory Committee, the USPAS Director selects highly-qualified instructors from university faculty and senior physicists and engineers from national laboratories and industry drawing on their practical experience in specific technical fields. The consortium laboratories have been highly supportive in encouraging their outstanding staff to teach at USPAS sessions, providing $\sim 2 / 3$ of our instructors. Selection for the USPAS faculty is generally considered to be a substantial professional recognition and honor. The result is a large pool of prospective instructors with expertise in a rich variety of forefront knowledge and methods. Consequently, our curriculum can cover the broad, multi-disciplinary spectrum of material that represents the field of beam physics and accelerator technology.

\section{Host universities}

An essential component of the USPAS is the nationwide pool of leading U.S. research universities from which the School selects as hosts for its semi-annual sessions of graduate-level courses. Universities that have sponsored past USPAS programs include Boston University, University of California campuses at Berkeley, Los Angeles, Santa Barbara, Santa Cruz and San Diego, University of Chicago, University of Colorado at Boulder, Cornell, Duke, Florida State University, Harvard, University of Illinois at UrbanaChampaign, Indiana University, MIT, Rice, Stanford, SUNY at Stony Brook, University of Texas-Austin, Vanderbilt, University of Washington at Seattle, and Yale. The host university vets all course content and faculty qualifications, assigns course numbers and maintains transcripts of the performance of for-credit students. The USPAS invites students from the host university to attend at no cost.

\section{The USPAS degree program}

Several years ago the USPAS established a Masters Degree program with Indiana University. Students earn credit toward the Indiana University diploma at USPAS/university-sponsored courses by selecting their USPAS course for Indiana University credit instead of the host university credit. For each program, USPAS instructors are given visiting professor appointments and USPAS courses are added to the Indiana 
University curriculum. Award of a Master of Science Degree requires 30 hours of credit with a grade point average of B or above; a maximum of 8 credit hours may be transferred; some credits earned at previous USPAS courses may be eligible for transfer. There is a strict five-year limit to obtain the Master of Science degree. Generally, students may complete the Master's degree program within 3 years. The maximum completion time is 5 years. At this time, we are unable to accept international students into the IU/USPAS Master's Degree Program. To date IU/USPAS Master's Degrees have been awarded to five students. Presently we have seven active students in the Master’s program.

In conjunction with USPAS, MIT's Departments of Physics and Electrical Engineering are working to establish an inter-disciplinary Ph.D. program in accelerator science and technology. Crucial to this program is a rigorous curriculum that is both relevant to the needs of accelerator-based science, and challenging and interesting to the students. A committee of faculty from both participating MIT Departments will develop and oversee the integrated curriculum. A standard part of the curriculum includes high-level graduate courses that are currently offered in physics, mathematics and engineering.

\section{Undergraduate outreach}

In 2008 the USPAS initiated a major effort in undergraduate outreach. In partnership with USPAS, Argonne National Laboratory and Fermilab have instituted the Lee Teng Undergraduate Internship. The purpose of the internship is to engage highly promising post-junior undergraduates in the study of and research in accelerator science and technology to encourage them to pursue graduate research and education in these fields. The secondary purposes are to build interest in and appreciation of accelerator physics and engineering at user faculty institutions and to develop distance-learning opportunities.

Selected interns are enrolled in the June Session USPAS undergraduate course, Fundamentals of Accelerators; the sponsoring laboratory pays for transportation to USPAS Session. USPAS awards a scholarship covering the USPAS fee (room, board, books, credit). During the remainder of the summer, students undertake research project under the guidance of a FNAL or ANL mentor scientist or engineer. The Teng Internship is open to any student from a US university who has just completed his/her junior year in physics, electrical or mechanical engineering. In 2008 year ANL and FNAL have selected 11 Teng interns. USPAS encourages other consortium laboratories to offer similar internships. 


\section{Session economics}

The fee for attending a USPAS session is $\$ 700$ (\$850 for late registration). This amount has been held constant over the past 15 years. The fee includes the tuition, half-board, and books. As previously noted students in good standing may request scholarship support to waive the fee and receive lodging. Roughly half our students qualify for and receive full financial support.

Since 1997 the average cost associated with each session has been $\sim \$ 180 \mathrm{~K}$ corresponding to an average cost per student of $\$ 1.5 \mathrm{~K}$. These costs are covered by a combination of registration fees plus the annual support $(\$ 30 \mathrm{~K})$ from the governing institutions. A large and essential in-kind contribution of the consortium not reckoned in that cost is the time and travel expenses of the instructors from the national laboratories. This segment of our faculty teaches as a part of their regular work assignment and does not receive any honorarium or additional compensation. Consequently, teaching costs primarily reflect the cost of stipends and travel expenses for instructors from universities, teaching assistants, graders and retired faculty who have no institutional support funds. The past decade has seen a slow trend toward increasing cost of the sessions due primarily to inflation of hotel and meal costs, both of which are highly location dependent. For example schools in California have been significantly more expensive, but they also draw a much larger number of students - thus keeping cost per student in line with other locations. Aggressive financial management has kept the annual average cost growth to $1.15 \%$ substantially less than inflation.

\section{Conclusion}

In its 21-year history of academic programs the USPAS has won a world-leading reputation in educating scientists and engineers in the physics and technology of particle accelerators. The rigorous, intense program of classroom and hands-on instruction attracts participants from throughout the world and provide an essential and highly cost effective national resource in accelerator science and technology.

\section{References:}

[AARD_2006] Report of the HEPAP Sub-panel on the Assessment of Advanced Accelerator Research and Development, July 11, 2006

[P5_2008] US Particle Physics: Scientific Opportunities A Strategic Plan for the Next Ten Years Report of the Particle Physics Project Prioritization Panel, 29 May 2008 at p. 61 